\title{
Períodos de Interferência das Plantas Daninhas na Cultura do ALGODOEIRO (Gossypium hirsutum)
}

\author{
Weed Interference Periods in Cotton Crop (Gossypium hirsutum)
}

\author{
SALGADO, T.P. ${ }^{2}$, ALVES, P.L.C.A. ${ }^{3}$, MATTOS, E.D. ${ }^{2}$, MARTINS, J.F. ${ }^{4}$ e HERNANDEZ, D.D. ${ }^{2}$
}

\begin{abstract}
RESUMO - Com o objetivo de determinar os efeitos de períodos de controle e de convivência das plantas daninhas na produtividade da cultura do algodoeiro (Gossypium hirsutum), cultivar Delta-Opal, realizou-se um experimento que constou de dois grupos de tratamentos. No primeiro, a cultura permaneceu livre da competição das plantas daninhas desde a emergência até $7,14,21,28,35,42,49,56,63$ dias e colheita (159 dias). No segundo, a cultura permaneceu em competição com a comunidade infestante desde a emergência até os mesmos períodos descritos para a primeira série de tratamentos. Dentre as espécies de plantas daninhas encontradas na área experimental, destacaram-se a tiririca (Cyperus rotundus), o fedegoso (Senna obtusifolia), a anileira (Indigofera hirsuta) e o capim-carrapicho (Cenchrus echinatus). Pelas condições edáficas, climáticas e florísticas sob as quais foi conduzida a cultura de algodão, o Período Anterior à Interferência (PAI) dessa comunidade que reduziu em 5\% a produtividade da cultura foi de oito dias após a emergência da cultura (DAE); o Período Total de Prevenção da Interferência (PTPI) foi de 66 DAE; e o Período Crítico de Prevenção da Interferência (PCPI) foi dos 8 aos 66 DAE.
\end{abstract}

Palavras-chave: período de convivência, matocompetição.

\begin{abstract}
In order to evaluate the effects of weed control and weed coexistence periods on cotton (Gossypium hirsutum) cultivar Delta Opal yield, an experiment was carried out consisting of two treatment groups. In the first, the crop was weed free from from emergence until 7, 14, $21,28,35,42,49,56,63$ days, and harvest (159 days) respectively. In the second group, the crop was in competition with the weed community from emergence until the same period, as described for the first series of treatment, respectively. Among the weed species found in the experimental area, the most important were purple nutsedge (Cyperus rotundus), sicklepod (Senna obtusifolia), indigo (Indigofera hirsuta) and sandbur (Cenchrus echinatus). The period after cotton plant emergence and previous to weed interference, which reduced cotton yield in 5\% was 8 days (DAE); the Total Period of Interference Prevention (TPIP) was 66 DAE and the Critical Period of Interference Prevention (CPIP) was between 8 to 66 DAE.
\end{abstract}

Key words: coexistence period, weed competition.

\section{INTRODUÇÃO}

O algodoeiro herbáceo (Gossypium hirsutum) é uma das principais culturas exploradas no Brasil, representando cerca de $15 \%$ da economia nacional, o que reflete a importância dessa malvácea na agricultura (Beltrão, 1993). No entanto, a cotonicultura nacional passou por sérias dificuldades na década de 90 , devido ao processo de abertura das fronteiras comerciais, o que proporcionou a entrada de produtos estrangeiros com menor custo de produção, diminuindo a área cultivada. Atualmente, a cultura do algodoeiro se recuperou e é a cultura

Recebido para publicação em 7/1/2002 e na forma revisada em 9/12/2002.

2 Pós-graduando em Produção Vegetal da Faculdade de Ciências Agrárias e Veterinária da Universidade Estadual de São Paulo - FCAV-UNESP, Rod. Prof. Paulo Donato Castellane, s/n, 14884-900 Jaboticabal-SP; ${ }^{3}$ Eng.-Agrônomo, Professor Assistente Doutor do DBAA/FCAV-UNESP. <plalves@ fcav.unesp.br>; ${ }^{4}$ Auxiliar Técnico do DBAA/FCAV-UNESP. 
anual que permite uma das maiores taxas de retorno, ainda que ofereça, em contrapartida, maiores riscos de perdas e demande alto nível técnico (Agrianual, 2001).

Como em qualquer cultura com fins comerciais, a presença de plantas daninhas interfere negativamente na cultura do algodoeiro, aumentando os custos de produção e diminuindo o valor da fibra (Laca-Buendia, 1990). O algodoeiro, por apresentar crescimento inicial lento (Azevedo et al., 1993), metabolismo fotossintético típico de plantas $\mathrm{C}_{3}$ (Benedict, 1984) e raízes superficiais (Freire \& Alves, 1976; Oliveira \& Silva, 1987), é considerado altamente sensivel à interferência das plantas daninhas (Beltrão \& Azevedo, 1994).

Os fatores que afetam o grau de interferência entre plantas daninhas e culturas agrícolas estão descritos em esquema proposto por Bleasdale (1960) e adaptado por Pitelli (1985). Segundo esse esquema, o grau de interferência depende de fatores ligados à própria cultura, à comunidade infestante, às condições específicas em que ocorre a associação culturacomunidade infestante e, finalmente, à época e extensão em que ocorreu a associação.

De maneira geral, pode-se dizer que, quanto maior for o período de convivência da cultura com a comunidade infestante, maior será o grau de interferência. No entanto, o grau de interferência dependerá sobremaneira da época do ciclo da cultura em que esse período for concedido.

Cia et al. (1999), Crowley \& Buchanan (1978) e Laca-Buendia (1990) afirmam que algumas espécies de plantas daninhas na cultura do algodoeiro, como capim-carrapicho (Cenchrus echinatus), capim-colchão (Digitaria sanguinalis), carrapicho-de-carneiro (Acanthospermum hispidum), picão-preto (Bidens pilosa) e corda-de-viola (Ipomea sp.), dificultam a colheita, além de prejudicarem a qualidade do produto.

Segundo Lorenzi (2000), o capim-carrapicho é uma planta daninha freqüente em lavouras anuais e perenes de quase todo o país, sendo particularmente temida em lavouras de algodão, onde, além de ferir as mãos e os braços dos colhedores e aderir em suas roupas, se fixam irreversivelmente na fibra, causando significativa desvalorização. Laca-Buendia
(1990) afirma que, devido ao alto teor de sílica em suas espiguetas, as máquinas de beneficiamento são afetadas, desgastando os dentes das serras e comprometendo a resistência das fibras.

Com relação à época e duração da convivência da cultura com as plantas daninhas, Pitelli \& Durigan (1984) chamam de período anterior à interferência (PAI) o período, a partir da semeadura, durante o qual a cultura pode conviver com as plantas daninhas sem que ocorra redução na sua produtividade. Os autores denominaram período total de prevenção à interferência (PTPI) o período, a partir da semeadura ou emergência da cultura, durante o qual as plantas daninhas devem ser controladas para que a cultura possa manifestar plenamente seu potencial produtivo.

Quando o PTPI é mais longo que o PAI, define-se um intervalo delimitado por ambos e denominado período crítico de prevenção de interferência (PCPI), que representa o período em que efetivamente a cultura deve ser mantida na ausência das plantas daninhas.

Quando ocorre o inverso, ou seja, o PAI é mais longo que o PTPI, o intervalo definido e delimitado por ambos não recebe nenhuma denominação especial. Nesse caso, apenas uma remoção das plantas daninhas, desde que feita dentro desse intervalo, permite que a cultura apresente produtividade plena. Esse tipo de comportamento viabiliza o uso de práticas instantâneas de controle das plantas daninhas.

Dessa forma, é conveniente que sejam realizadas pesquisas para atender às necessidades de diferentes regiões e conhecer a sensibilidade dos cultivares de algodão à interferência das plantas daninhas, fornecendo subsídios para o planejamento de programas de manejo das plantas daninhas nesta cultura. Assim, este trabalho objetivou determinar os efeitos de períodos de controle e de convivência das plantas daninhas na produtividade da cultura do algodoeiro (Gossypium hirsutum), cultivar Delta Opal, em Jaboticabal-SP.

\section{MATERIAL E MÉTODOS}

O presente trabalho foi instalado em campo, em área experimental da FCAVJ/UNESP, no dia 28 de novembro do ano agrícola 2000/2001. 
Os tratamentos implantados após a emergência das plântulas de algodão constaram de dois grupos. No primeiro, a cultura, a partir de sua emergência, permaneceu livre da competição das plantas daninhas durante determinados períodos: 0-7 dias, 0-14 dias, 0-21 dias, 0-28 dias, 0-35 dias, 0-42 dias, 0-49 dias, 0-56 dias, 0-63 dias e 0-colheita (159 dias). Após esses períodos, as plantas daninhas que emergiram nas parcelas cresceram livremente. No segundo grupo, procedeu-se ao contrário: a cultura, a partir de sua emergência, permaneceu em competição com a comunidade infestante durante os períodos mencionados para o primeiro grupo de tratamentos.

A remoção das plantas daninhas ao final de cada período de convivência inicial, bem como a manutenção semanal dessas parcelas livres da presença das plantas daninhas até o fechamento das entrelinhas pela cultura, foi realizada com capina manual (enxada). Os períodos crescentes de controle também foram obtidos com freqüentes operações de capina manual, que eram interrompidas à medida que se atingia o final de cada período.

O delineamento experimental utilizado foi o de blocos casualizados, em quatro repetições. O espaçamento entre linhas foi de 0,9 metro, e as parcelas experimentais constaram de quatro linhas com cinco metros de comprimento, considerando como área útil os três metros das duas linhas centrais.

Ao término de cada período de convivência e ao início de cada período de controle, as plantas daninhas presentes em duas áreas amostrais de $0,25 \mathrm{~m}^{2}$, tomadas aleatoriamente nas parcelas, foram identificadas, contadas e removidas. Dessas plantas obteve-se, após secagem em estufa com circulação forçada de ar a $70{ }^{\circ} \mathrm{C}$, a massa da matéria seca total de cada parcela.

Os dados de densidade e massa da matéria seca da comunidade infestante foram extrapolados para número de plantas $\mathrm{m}^{-2}$ e gramas de matéria seca $\mathrm{m}^{-2}$, respectivamente. Esses dados foram submetidos à análise de regressão em função do número de dias após a emergência da cultura. Com a finalidade de se avaliar a importância relativa das espécies componentes da comunidade infestante, calcularam-se, para cada população, a densidade relativa (Curtis \& McIntosh, 1950) e a dominância relativa (Mueller-Doubois \& Ellemberg, 1974).

Os dados de produção (fibra + caroço) foram analisados estatisticamente dentro de cada grupo de tratamentos (controle e convivência), sendo submetidos à análise de regressão segundo o modelo sigmoidal (Microcal Origin, versão 4.0). Os limites dos períodos de interferência foram determinados tolerando-se perda máxima de produção de $5 \%$ em relação àquela obtida nas parcelas mantidas no limpo durante todo o ciclo (Kuva, 1999). Os dados de precipitação pluvial foram obtidos no laboratório de agrometeorologia da FCAVJ (Tabela 1).

Tabela 1 - Precipitação pluvial na região de Jaboticabal-SP, ao longo dos meses referentes ao experimento. Jaboticabal-SP, 2000/01

\begin{tabular}{|l|c|}
\hline Meses $(2000-2001)$ & Precipitação $(\mathrm{mm})$ \\
\hline Novembro & 132,4 \\
Dezembro & 207,7 \\
Janeiro & 208,7 \\
Fevereiro & 81,8 \\
Março & 101,9 \\
Abril & 43,8 \\
Maio & 92,0 \\
Junho & 5,0 \\
\hline
\end{tabular}

\section{RESULTADOS E DISCUSSÃO}

A comunidade infestante era composta por 25 espécies de plantas daninhas, com predominância de dicotiledôneas (64\%). Dentre estas, destacaram-se, em número de espécies, a família Asteraceae (Compositae), com cinco espécies, seguida pela Amaranthaceae e Euphorbiaceae, ambas com duas espécies (Tabela 2). Dentre as monocotiledôneas, verificou-se a presença de uma espécie pertencente à família Cyperaceae, uma à Commelinaceae e sete à família Poaceae (Graminae), sendo esta a que apresentava maior densidade, representando $28 \%$ da comunidade infestante.

Segundo Clark (1971), as espécies de plantas daninhas que se desenvolvem na mesma área da cultura influenciam, em parte, o grau de competição, pois as habilidades competitivas variam com a espécie. Supõe-se que quanto 
mais duas espécies sejam fisiologicamente semelhantes, e, muitas vezes, isso está relacionado à classificação taxonômica, mais semelhantes são suas necessidades e mais intensa é a sua competição pelos fatores que se encontram em quantidades limitadas no ecossistema comum.

Em termos de densidade, a comunidade infestante estava estabelecida aos sete dias após a emergência (DAE), indicando rápida germinação e emergência das plantas daninhas (Figura 1). Essa comunidade atingiu o seu máximo aos $28 \mathrm{DAE}$, com cerca de 56 plantas $\mathrm{m}^{-2}$, e assim se manteve até os 35 DAE. Ao final desse período, houve redução na densidade de infestação. Essa redução foi observada até o final do ciclo da cultura (159 DAE), quando a comunidade infestante era menos densa, com 3,19 plantas $\mathrm{m}^{-2}$. Esse resultado deve-se possivelmente à interação entre o sombreamento imposto pela cultura à comunidade infestante, o ciclo de vida curto de algumas espécies de plantas daninhas e a redução na precipitação pluvial, a partir de fevereiro (Tabela 1). A massa de matéria seca da comunidade infestante aumentou até os 120 DAE, quando atingiu o máximo de $620 \mathrm{~g} \mathrm{~m}^{-2}$ (Figura 2). A partir dessa época verificou-se redução na massa de matéria seca, que, provavelmente, se deveu à senescência das plantas daninhas ou à mortalidade de espécies de ciclos mais curtos.

Por ocasião da colheita do algodão, aos 159 DAE, a comunidade infestante havia acumulado $605,14 \mathrm{~g} \mathrm{~m}^{-2}$, o que equivale a 189,70 g planta $^{-1}$.

Tabela 2 - Comunidade infestante da cultura do algodão no decorrer do período experimental, com respectivos códigos internacionais. Jaboticabal-SP, 2000/01

\begin{tabular}{|c|c|c|c|}
\hline Família & Espécie & Nome popular & Código internacional \\
\hline \multicolumn{4}{|c|}{ Dicotiledoneae } \\
\hline Amaranthaceae & $\begin{array}{l}\text { Alternanthera tenella } \\
\text { Amaranthus deflexus }\end{array}$ & $\begin{array}{l}\text { Apaga-fogo } \\
\text { Caruru }\end{array}$ & $\begin{array}{l}\text { ALRTE } \\
\text { AMADE }\end{array}$ \\
\hline Asteraceae & $\begin{array}{l}\text { Acanthospermum hispidum } \\
\text { Bidens pilosa } \\
\text { Blainvillea biaristata } \\
\text { Emilia sonchifolia } \\
\text { Parthenium hysterophorus }\end{array}$ & $\begin{array}{l}\text { Carrapicho-de-carneiro } \\
\text { Picão-preto } \\
\text { Blaenvilha } \\
\text { Falsa-serralha } \\
\text { Losna-branca }\end{array}$ & $\begin{array}{l}\text { ACNHI } \\
\text { BIDPI } \\
\text { BLARH } \\
\text { EMISO } \\
\text { PTNHY }\end{array}$ \\
\hline Caesalpiniaceae & Senna obtusifolia & Fedegoso & CASOB \\
\hline Convolvulaceae & Ipomoea sp. & Corda-de-viola & --- \\
\hline Euphorbiaceae & $\begin{array}{l}\text { Croton glandulosus } \\
\text { Euphorbia heterophylla }\end{array}$ & $\begin{array}{l}\text { Gervão } \\
\text { Leiteiro }\end{array}$ & $\begin{array}{l}\text { CVNGL } \\
\text { EUPHY }\end{array}$ \\
\hline Fabaceae & Indigofera hirsuta & Anileira & INDHI \\
\hline Malvaceae & Sida sp. & Guanxuma & --- \\
\hline Portulacaceae & Portulaca oleracea & Beldroega & POROL \\
\hline Rubiaceae & Richardia brasiliensis & Poaia-branca & RCHBR \\
\hline Solanaceae & Solanum americanum & Maria-pretinha & SOLAM \\
\hline \multicolumn{4}{|c|}{ Monocotiledoneae } \\
\hline Poaceae & $\begin{array}{l}\text { Brachiaria plantaginea } \\
\text { Cenchrus echinatus } \\
\text { Cynodon dactylon } \\
\text { Digitaria horizontalis } \\
\text { Eleusine indica } \\
\text { Panicum maximum } \\
\text { Panicum maximum }\end{array}$ & $\begin{array}{l}\text { Capim-marmelada } \\
\text { Capim-carrapicho } \\
\text { Grama-seda } \\
\text { Capim-colchão } \\
\text { Capim-pé-de-galinha } \\
\text { Capim-colonião } \\
\text { Capim-coloninho }\end{array}$ & $\begin{array}{l}\text { BRAPL } \\
\text { CCHEC } \\
\text { CYNDA } \\
\text { DIGHO } \\
\text { ELEIN } \\
\text { PANMA } \\
\text { PANMA }\end{array}$ \\
\hline Commelinaceae & Commelina benghalensis & Trapoeraba & COMBE \\
\hline Cyperaceae & Cyperus rotundus & Tiririca & CYPRO \\
\hline
\end{tabular}


A média da densidade relativa do fedegoso foi de 3,94\% até os 63 DAE e, em seguida, aumentou, chegando a 39,22\% aos $159 \mathrm{DAE}$ (Figura 3). A média de densidade relativa total das demais espécies presentes na área foi de $17,68 \%$. Essa densidade relativa manteve-se em torno de $8,75 \%$ até os $63 \mathrm{DAE}$, aumentando até chegar a 60,78\%, aos 159 DAE. Esse aumento final nas densidades relativas dessas espécies coincide com a redução nas densidades relativas de tiririca, capim-carrapicho e anileira, mostrando a importância que o fedegoso e as demais espécies apresentaram no final do ciclo da cultura.

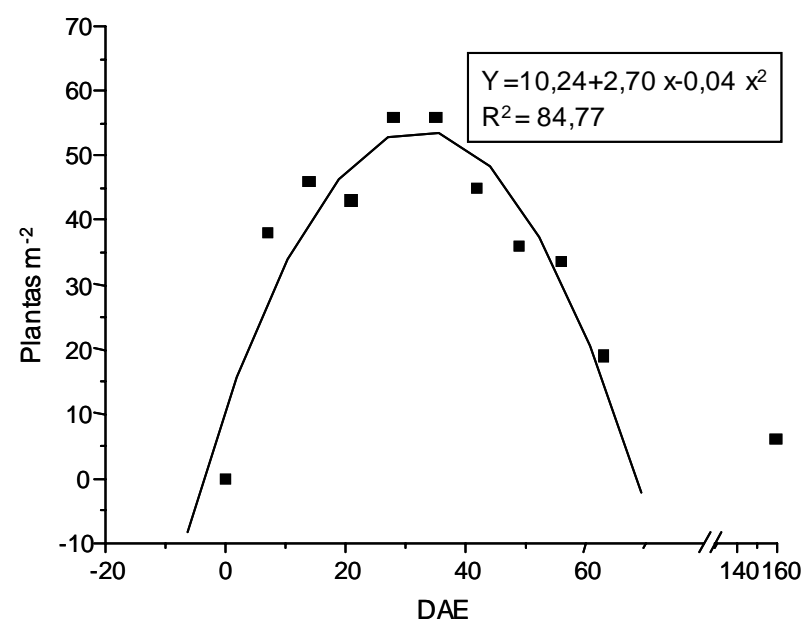

Figura 1 - Densidade de plantas daninhas presentes na área experimental em função do número de dias após emergência (DAE) do algodão. Jaboticabal-SP, 2000/01.

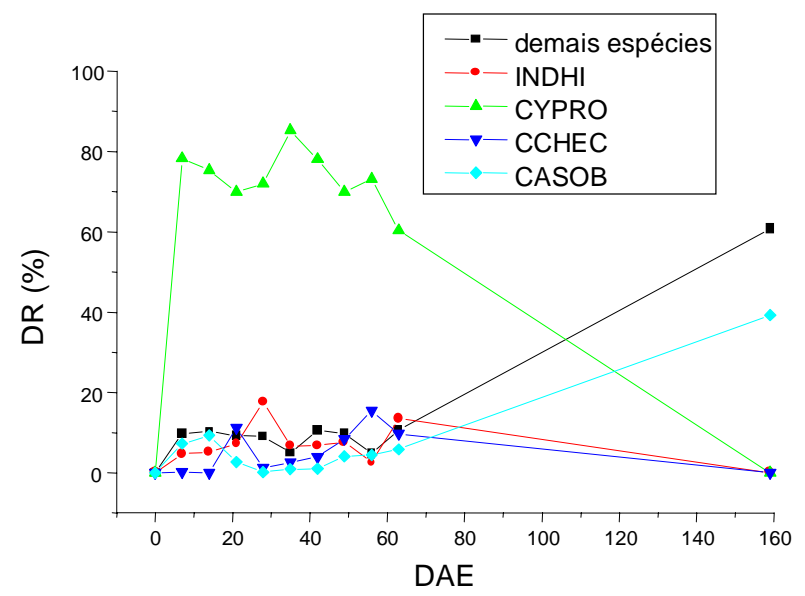

Figura 3 - Densidade relativa (DR) das plantas daninhas presentes na área experimental em função do número de dias após emergência (DAE) do algodão. Jaboticabal-SP 2000\01.
A tiririca foi a espécie predominante, apresentando média de 44,79\%; entretanto, sua densidade relativa caiu drasticamente a partir dos 56 DAE. Verificou-se o mesmo comportamento com o capim-carrapicho e com a anileira, que mantiveram uma média de 5,81 e 7,93\%, respectivamente, até os $63 \mathrm{DAE}$ e, em seguida, perderam importância, apresentando aos 159 DAE densidade relativa próxima de zero.

Os resultados de dominância relativa (DoR) (Figura 4), que representa a participação percentual da massa da espécie em relação à massa acumulada pela comunidade infestante, foram semelhantes aos da DR (Figura 3).

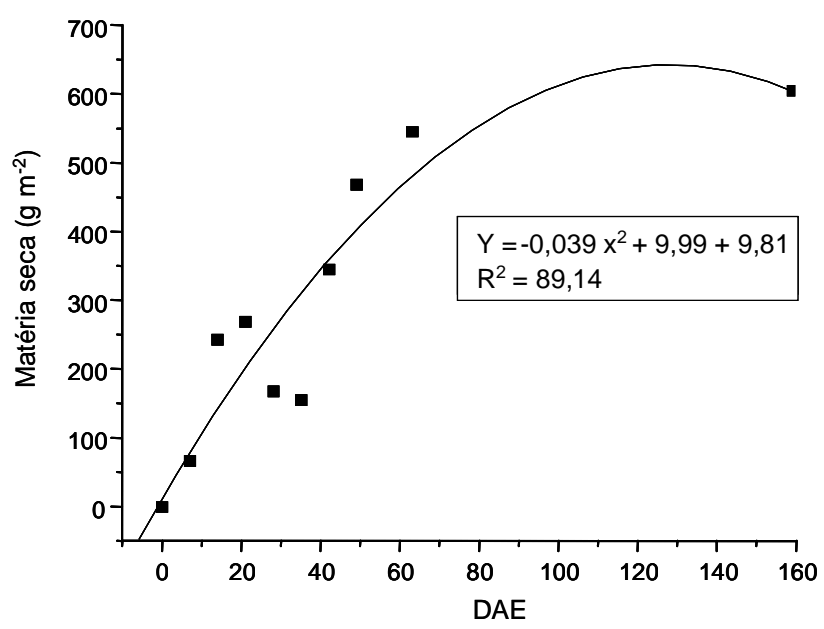

Figura 2 - Massa da matéria seca das plantas daninhas presentes na área experimental em função do número de dias após emergência (DAE) do algodão. Jaboticabal-SP, 2000/01.

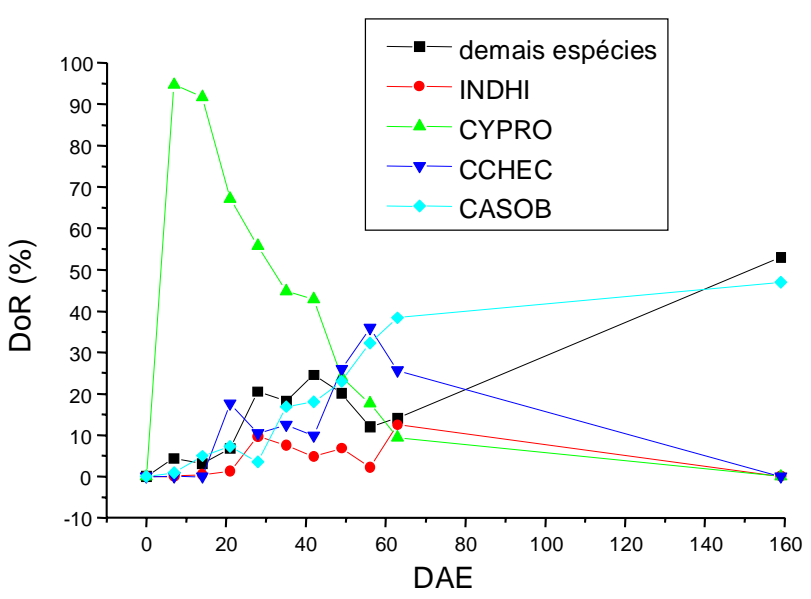

Figura 4 - Dominância relativa (DoR) das plantas daninhas presentes na área experimental em função do número de dias após emergência (DAE) do algodão. Jaboticabal-SP, 2000/01.

Planta Daninha, Viçosa-MG, v.20, n.3, p.373-379, 2002 
A tiririca apresentou DoR máxima logo aos 7 DAE $(94,67 \%)$, e a partir de então houve queda acentuada até o final do ciclo da cultura. Essa redução na DoR da tiririca foi acompanhada pelo aumento na DoR de fedegoso, capim-carrapicho e demais espécies. Esse aumento foi acentuado, iniciando-se aos $14 \mathrm{DAE}$ para o capim-carrapicho e aos 21 DAE para as demais espécies. A DoR do fedegoso continuou a aumentar até o final do ciclo, chegando a 46,97\% aos 159 DAE. Para o capim-carrapicho, a DoR chegou a $35,86 \%$ aos 56 DAE, decrescendo logo após, até praticamente zero no final do ciclo, quando a espécie foi observada em reboleiras. As demais espécies apresentaram DoR média de $17,68 \%$, sendo mais representativas a partir dos 28 DAE, com 20,60\% de DoR. A partir dessa data, a DoR desse grupo de espécies manteve-se estável até os $49 \mathrm{DAE}$, após os quais houve queda seguida de aumento, chegando a 53,03\% no final do ciclo.

A dominância da anileira atingiu o máximo aos 63 DAE (12,56\%), decrescendo em seguida, até estar praticamente ausente no final do ciclo.

Nas condições edáficas, climáticas e florísticas que ocorreram durante o período experimental, bem como na presença da comunidade infestante composta predominantemente por tiririca no estabelecimento da cultura e por fedegoso no final do seu ciclo, verificou-se que o PAI dessa comunidade, que reduziu em 5\% a produtividade da cultura do algodão, cultivar Delta Opal, foi de oito dias após a emergência da cultura (DAE), o PTPI foi de 66 DAE e o PCPI foi dos 8 aos 66 DAE (Figura 5). A interferência das plantas daninhas neste cultivar pode resultar em perdas de até $97 \%$ na produtividade.

Kawaguchi (1991) verificou que a cultura do algodão cv. IAC 20, em Jaboticabal, necessitou ficar 28 dias após a semeadura livre da interferência da comunidade infestante (PAI), com predominância de caruru, carrapicho-decarneiro e capim-carrapicho, para que não ocorressem prejuízos qualitativos e quantitativos em sua produção. Em revisão feita por Furuhashi (1999), citando 11 trabalhos com essa cultura, o PAI variou de 10 a 40 dias, enquanto o PTPI variou de 35 a 60 dias.

Segundo Forster \& Paulo (1984), as gramíneas prejudicam a produção se conviverem com o algodão por um período de 10 e 20 dias. As dicotiledôneas iniciam a redução na produção após sua permanência junto com a cultura por um período entre 20 e 30 dias, a contar da emergência do algodão.

A convivência das plantas de algodão e das plantas infestantes durante todo o ciclo da cultura pode resultar em reduções que variam de 68 a 95\% na produtividade, sem contar os inconvenientes na colheita (Cia et al., 1999).

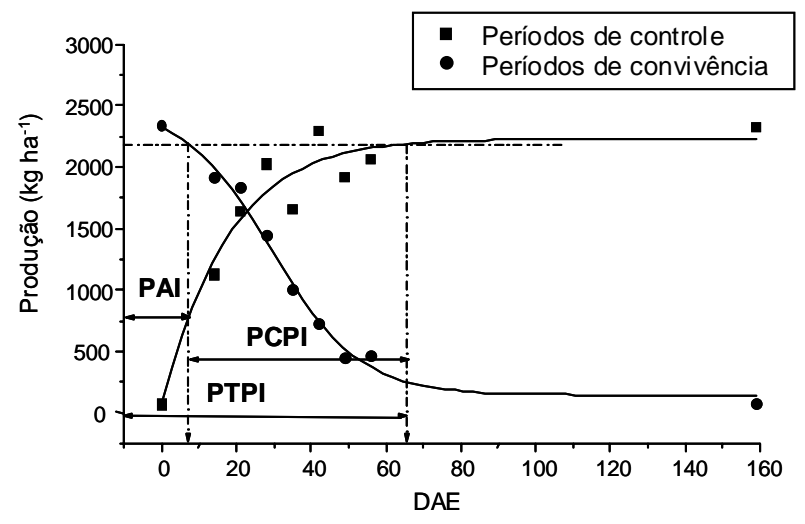

Figura 5 - Período anterior à interferência (PAI), período total de prevenção da interferência (PTPI) e período crítico de prevenção da interferência (PCPI), tolerando-se no máximo uma perda de $5 \%$ na produtividade (fibra e caroço) da cultura. Jaboticabal-SP, 2000/01.

Estudando a relação entre tiririca (Cyperus rotundus) e algodão, Blanco et al. (1991) verificaram que populações que emergem no solo após seis semanas do plantio do algodoeiro não causam prejuízos à planta cultivada. Os autores observaram que, quanto maior foi o número de tubérculos por área, menores foram os pesos da matéria fresca e seca das maçãs, as folhas, o caule e a altura das plantas de algodão. Densidades populacionais a partir de um tubérculo por $0,141 \mathrm{~m}^{2}$ provocaram diminuições significativas e lineares no desenvolvimento e na produção de plantas de algodão.

\section{LITERATURA CITADA}

AGRIANUAL 2001: anuário da agricultura brasileira. São Paulo: FNP Consultoria \& Comércio, 2001. p. 153.

AZEVEDO, D. M. P. et al. Manejo de plantas daninhas no cultivo do algodoeiro herbáceo. Campina Grande: EMBRAPA-CNPA, 1993, 11 p. (Comunicado Técnico, 35) 
BELTRÃO, N. E. Recomendações técnicas para o cultivo do algodoeiro herbáceo de sequeiro e irrigado nas regiões nordeste e norte do Brasil. Campina Grande: EMBRAPACNPA, 1993. 72 p. (Circular Técnica, 17).

BELTRÃO, N. E.; AZEVEDO, D. M. P. Controle de plantas daninhas na cultura do algodoeiro. Campina Grande: EMBRAPA-CNPA, 1994. 154 p.

BENEDICT, C. R. Physiology. In: KOHEL, R. J.; LEWIS, C. F. (Eds.). Cotton. Madison: Americam Society of Agronomy, 1984. p. 151-200.

BLANCO, H. G.; ARËVALO, R. A.; CHIBA, S. Convivência de populações de Cyperus rotundus $\mathrm{L}$. com plantas de algodoeiro herbáceo. Pesq. Agropec. Bras., v. 26, n. 2, p. 169-176, 1991.

BLEASDALE, J. K. A. Studies on plant competition. In: HARPER, J. L. The biology of weeds. Oxford: Blackwell Scientific, 1960. p. 133-142.

CIA, E.; FREIRE, E. C.; SANTOS, W. J. (Eds.). Cultura do algodoeiro. Piracicaba: POTAFOS, 1999. p. 101-157.

CLARK, G. L. Elementos de ecologia. Barcelona: Omega, 1971. $534 \mathrm{p}$

CROWLEY, R. H.; BUCHANAN, G. A. Competition of formmimornig glery (Ipomea sp.) species with cotton (Gossypium hirsitum L.). Weed Sci., v. 26, p. 484-488, 1978.

CURTIS, J. P.; McINTOSH, R. P. The interrelations of certain analytic and synthetic phytosociological characters. Ecology, v. 31, p. 434-5, 1950.

FORSTER, R.; PAULO, E. M. Período de competição de populações de gramíneas e dicotiledôneas, vegetando em separado, na cultura do algodão. In: CONGRESSO BRASILEIRO DE HERBICIDAS E PLANTAS DANINHAS, 15., 1984, Belo Horizonte. Resumos... Belo Horizonte: 1984. p. 38.

FREIRE, E. C.; ALVES, E. J. Estudo do sistema radicular do algodoeiro em diferentes espaçamentos. In: FREIRE, E. C.; SOUZA, L. S.; ALVES, E. J. Experimentação algodoeira nos Estados da Bahia e Sergipe, 1971/74. Salvador: EMBRAPA- Representação do Estado da Bahia, 1976. p. 81-86. (Comunicado Técnico, 1).
FURUHASHI, S. Combinação de herbicidas aplicados em PPI, Pré e em Pós-emergência na cultura do algodão (Gossypium hirsutum L.). Jaboticabal: UNESP, 1999. 106 p. Dissertação (Mestrado em Produção Vegetal) Universidade Estadual Paulista, Jaboticabal, 1999.

KAWAGUCHI, I. T. Determinação do período anterior à interferência para o algodoeiro (Gossypium hirsutum L.) e efeitos da densidade e da deficiência hídrica na competição com o capim-carrapicho (Cenchrus echinatus L.). Jaboticabal: UNESP. 1991. 90 p. Trabalho de (Monografia em Agronomia) - Universidade Estadual Paulista, Jaboticabal, 1991.

KUVA, M.A. Efeitos de períodos de controle e de convivência das plantas daninhas na cultura de cana-deaçúcar (Saccharum sp.) no Estado de São Paulo. Piracicaba: ESALQ, 1999. 74 p. Dissertação (Mestrado em Fitotecnia) - Escola Superior de Agricultura "Luiz de Queiroz", 1999.

LACA-BUENDIA, J. P. C. Controle de plantas daninhas em algodoeiro. Inf. Agropec., v. 15, n. 166, p. 37-47, 1990.

LORENZI, H. Plantas daninhas do Brasil: terrestres, aquáticas, parasitas e tóxicas. 3.ed. Nova Odessa: Instituto Plantarum, 2000. p. 251 e 296

MUELLER-DOUBOIS, P.; ELLEMBERG, H. Aims and methods of vegetation ecology. New York: John Willey \& Sons, 1974. 547 p.

OLIVEIRA, F.A.; SILVA, J. J. S. Uso consecutivo e desenvolvimento radicular do algodoeiro herbáceo (Gossypium hirsutum L.). Salvador: EPABA, 1987. 22 p. (Boletim de Pesquisa, 8).

PITELLI, R. A. Interferência das plantas daninhas em culturas agrícolas. Inf. Agropec., v. 11, n. 129, p. 16-27, 1985.

PITELLI, R. A.; DURIGAN, J. C. Terminologia para períodos de controle e convivência das plantas daninhas em culturas anuais e bianuais. In: CONGRESSO BRASILEIRO DE HERBICIDAS E PLANTAS DANINHAS, 15., 1984, Belo Horizonte. Resumos... Belo Horizonte: 1984. p. 37. 